\title{
LINGUISTIC ANALYSIS OF USER MOTIVATIONS OF INFORMATION CONTENT FOR UNIVERSITY ENTRANT'S WEB-FORUM
}

\author{
Pavlo Zhezhnych 1), Anna Shilinh ${ }^{2)}$, Viktor Melnyk ${ }^{3,4)}$ \\ 1) Department of Social Communication and Information Activities, Lviv Polytechnic National University, \\ 12 S. Bandery str., Lviv, 79000, Ukraine, pavlo.i.zhezhnych@lpnu.ua \\ 2) Department of Information Systems and Networks, Lviv Polytechnic National University, \\ 12 S. Bandery str., Lviv, 79000, Lviv, Ukraine, AnnaShiling@gmail.com \\ 3) Department of Information Technologies Security, Lviv Polytechnic National University, \\ 12 S. Bandery str., Lviv, 79000, Lviv, Ukraine \\ 4) Faculty of Mathematics, IT and Landscape Architecture, John Paul II Catholic University of Lublin, \\ Konstantynow 1H, Lublin, Poland, vmelnyk@kul.lublin.pl
}

Paper history:

Received 3 December 2018

Received in revised form 21 December 2018

Accepted 11 March 2019

Available online 31 March 2019

Keywords:

web-forum;

entrant;

higher education institution;

content;

linguistic method;

motivation.

\begin{abstract}
Educational web-forums are an effective source of meeting the information and communication needs of the participants in educational activities. Information content of the educational web-forum for entrants is a reflection of the motivational intentions of communication participants who publish posts in the web-community. The subjects of the posts or the choice of the thematic section characterize the motivational intentions of both sides of the communicative activity. It should be borne in mind that motivational intentions are based not only on the technical, but also on the psychological aspects of the author's activities. So, an important task is to carry out a computer-linguistic analysis of the peculiarities of the formation of the information content of an educational web-forum for entrants created by motivated users. This article discusses the linguistic analysis of individual postings that form the content of a web-forum with template key phrases. Participant communications are divided into parts that present information about certain motivational intentions of the participants in the entry campaign. Linguistic analysis of motivational intentions of higher educational institutions and potential entrants is also contained in the article.
\end{abstract}

Copyright (C) Research Institute for Intelligent Computer Systems, 2019. All rights reserved.

\section{INTRODUCTION}

Specialized web-forums for university entrants occupy an important place in the planning process of providing educational services. They establish a "feedback" between the participants in educational activities, namely, a higher education institution (HEI) and a potential entrant or a student.

Information content of specialized web-forums for entrants is the communication activity of the participants of the discussion on the chosen educational section, taking into account the interests of the participants of the communication [1].

An analysis of the content that is generated by the activity of those involved in a given entry campaign plays an important role in the planning process for providing educational services. Namely, a potential entrant receives the information he/she needs for a certain aspect of providing educational services at the HEI, so that he can get it he/she can start an appropriate thematic discussion (active participant of communication), or even having looked through the dialogue of the necessary section (passive participant of communication), and the university, pushing away from topics and educational discussions, can plan a set of entrants, and improve their activities.

A large number of educational content, during all periods of the formation of information content, depends on the motivational intentions of the authors of the papers. That is why it requires constant processing and updating, especially during periods of greatest activity of communication participants. Consequently, the analysis of the formation of 
information content of the educational web forum for entrants will allow us to quickly remove and process the necessary information, and react to both sides of communicative activity.

Today, there are several areas for studying the communicative activities of virtual community members and the importance of informational content of educational web-forums.

The formal structure of on-line communities based on web-forums is described in [1-3]. The peculiarities of educational web-forums are characterized in researches $[4,5]$. Work on the development of educational web-forums [6] is devoted to the analysis.

Analyzing the general structure of web-forums [1] and the structure of web-forums for university entrants, it is possible to highlight such features as the list of thematic sections. Namely, the "Entry Rules", "Entry exams", "Directions of preparation", "Reception of documents", "Privileges", "Organization of social and household activities of universities". These thematic sections are fixed in the continuation of many entry campaigns. The names of these thematic sections may differ in exact wording, although the content of their information content is persistent. The number of sections can be determined by the university itself, or formed in the process of communicative activity.

The papers [7, 8] contain an analysis of the peculiarities of the content formation of educational web-forums for higher education. In particular, the peculiarities of educational web forums for higher education institutions, namely the role of their information content, are discussed in the paper [9].

The study of linguistic characteristics that affect communication and social interaction in educational web-forums is considered in [10-13]. In particular, the recognition of fragments of posts on websites is described in [14].

Content analysis as a methodology for studying on-line communities is described in [15-17]. In particular, the features of communicative interaction in virtual communities on the basis of web-forums, namely the detection of manipulations in real-time, are described in [18]. The analysis of Internet communications based on motivational intentions is described in papers $[19,20]$. The analysis of the trends of the choice of an entrant of an educational establishment is the main topic of research in works [21].

But none of the research areas focuses on the possibility of planning educational services based on an analysis of the peculiarities of the formation of information content by motivated participants of these web communities in relation to a certain period of the entry campaign.

\section{ANALYSIS OF THE MOTIVATIONAL ACTIVITY OF THE AUTHOR OF THE POST}

By analyzing the content of educational webforums for university entrants, it is worth considering that each participant in the discussion has its own goal of communicating with other members of the educational community. Formation of the content of the selected forum depends on the motivational intentions of the author of the post. And this, in turn, forms a certain behavioral model and informational role of the participant of the web community.

With the help of lexical, syntactic and stylistic characteristics of the post, one can identify the main motivation of its author and adjust its actions to communicative activities in the community. The intentions of the author on the direct affect the nature of the content of information and the course of communication activities in general. To reveal the motivational activity of the author, we will use a linguistic method for analyzing the contents of webforum posts for entrants using markers.

The marker of motivation is the phrases, words, parts of the sentence that somehow characterize the author's motivation for posting in the on-line community [11], that is, verbal reflection of the author's motivational intentions:

$$
\text { EducMotivMarker }=\left\{\text { Marker }_{i}\right\}_{i=1}^{N(M)},
$$

where $N(M)$ - number of markers in the text of the educational post.

Types of participants' motivations markers in communicative activities are changing in relation to thematic sections and time periods of activity of the participants in the educational discussion. Several markers may relate to one period of an introductory campaign, but in different time periods. There are several motivational markers in the post.

By analyzing web-forums for entrants, the motivation of the posts is a tuple of two elements:

$$
\text { Motiv }_{i}=\left\langle\text { EntranceMotiv }_{i}, \text { HEIMotiv }_{i}\right\rangle,
$$

where EntranceMotiv E $_{i}$ - benefit for potential entrant, HEIMotiv $v_{i}$ - benefit for higher education institution.

\subsection{ANALYSIS OF THE ENTRANT'S MOTIVATIONAL INTENTIONS}

The motivational intention of a potential entrant is a tuple of three elements: 


$$
\text { EntranceMotiv }_{i}=\left\langle\begin{array}{c}
\text { MInforation }_{i}, \\
\text { MAffect }_{i}, \quad \\
\text { MExperience }_{i}
\end{array}\right\rangle,
$$

where

$$
\text { MInforation }_{i}==
$$

$\left\{\text { Marker }_{j}^{\left(\text {MInforation }_{i}\right)}\right\}_{j=1}^{N\left(\text { MInforation }_{i}\right)} \subset$

EducMotivMarker - the information needs of a potential i-th entrant,

MAffect ${ }_{i} \subset$ EducMotivMarker - the need to provide false information, MExperience $_{i} \subset$ EducMotivMarker - the need to share experiences.

The information needs of a potential entrant are the set of motivational markers regarding the information needs of entrants characterizing the interest of the contributors to obtain the necessary information for decision-making in a particular situation related to a particular entry campaign ('where to apply', 'how to send', 'expect answers', etc.):

For each type of markers MInformation from (3) we define the indicator as a fuzzy set:

$$
\begin{aligned}
& \text { InformationIndicator(MInforation } \text {. }_{i} \text { ) } \\
& \left.=\left\{\begin{array}{c}
\text { Marker }_{j}^{\left(\text {MInforation }_{i}\right)} \\
\left.\omega \text { (MInforation }_{i}\right)_{j}
\end{array}\right\rangle\right\}_{j=1}^{N\left(\text { MInforation }_{i}\right)}
\end{aligned}
$$

where $\omega\left(\text { MInforation }_{i}\right)_{j} \in[0,1]$ - the measure of correspondence of the $\mathrm{j}$-th marker to the motivational intent of the i-th entrant.

The need to provide false information is the set of motivational markers that express the provocative need of entrants that characterize the incorrect behavior of a participant in communicative activities ('what to do here', 'who is here posting', etc.) Inaccuracy is manifested in the fact that the participant provides false information or provokes disputes among participants in communicative activities, or "clogging" the virtual space of a webforum (spamming, flooding).

The need to share experiences is the set of motivational markers that express the need to share experiences that characterize this need for a participant in communicative activities ('I betrayed', 'brought', 'deducted', etc.). The participants in the conversation share experience or provide advice on how to resolve a particular situation within a specific entry campaign.

Formal definitions of indicators the last two indents are constructed like (4).

\subsection{ANALYSIS OF THE MOTIVATION OF} THE ACTIVITY OF A HIGER EDUCATIONAL INSTITUTION

Determine the components of motivation for a higher educational establishment:

Motivational intentions of the university are presented by a tuple of two elements:

$$
\text { HEIMotiv }_{i}=\left\langle\begin{array}{c}
\text { MOrganization }_{i,} \\
\text { MRelevance }_{i}
\end{array}\right\rangle,
$$

where MOrganization $_{i}$ - the need to organize the information space of the web forum, MRelevance $_{i}$ - need to determine the relevance of the post.

The need to organize the information space of a web-forum is to timely identify a thematic post, identify its topic and problem, which is described in the text part, and provide the necessary information, or redirect the contributor to the necessary discussion section when it is impossible to give a full answer online.

The need to organize the information space of a web-forum is a tuple of six elements:

$$
\begin{gathered}
\text { MOrganization }_{i}= \\
\text { EntryMarker }_{i}, \text { ExaminationMarker }_{i} . \\
\left\langle\text { DirectionMarker }_{i}, \text { DocumentMarker }_{i}\right\rangle, \\
\text { PrivilegesMarker }_{i}, \text { SocialMarker }_{i}
\end{gathered}
$$

where

$\left\{\text { EntryMarker }_{i}\right\}_{i=1}^{N(\text { EntryMarker })} \subset$

EntryMarker $=$

EducMotivMarker - markers motivation for entry rules, ExaminationMarker ${ }_{i}$ - markers motivation for entrance exams, DirectionMarker $_{i} \subset$ EducMotivMarker - markers of motivation regarding the proposed directions of training, DocumentMarker $_{i} \subset$ EducMotivMarker markers of motivation to accept documents, PrivilegesMarker $_{i} \subset$ EducMotivMarker

markers of motivation that characterize the benefits of an entry campaign to other entrants, SocialMarker $_{i} \subset$ EducMotivMarker $\quad-$ the markers of the motivation of the participants in the entry campaign regarding the social and living conditions of education and the educational process itself at the universities.

Let's consider types of markers of motivation of higher educational institutions concerning the need for organizing the information space of a webforum:

- A set of markers of motivation regarding admission rules that characterize the preparation of communication participants to the entry 
campaign ('admission committee', 'electronic introduction', 'originals', etc.).

For each type of markers EntryMarker from (6), the indicator for the set of these markers is defined as follows:

$$
\begin{aligned}
& \text { EntryIndicator }\left(\text { EntryMarker }_{i}\right) \\
& \left\{\begin{array}{c}
\left.{\text { Marker }\left(\text { EntryMarker }_{i}\right)_{j},}_{\omega\left(\text { EntryMarker }_{i}\right)_{j}}^{N(\text { EntryMarker })}\right\rangle
\end{array}\right\}_{j=1}
\end{aligned}
$$

where $\omega\left(\text { EntryMarker }_{i}\right)_{j} \in[0,1]-$ the measure of correspondence of the $\mathrm{j}$-th marker to the motivational intent of the $\mathrm{i}$-th entrant.

- A set of markers of motivation for entrance exams that characterize the stage of conducting creative competitions in an educational institution or specify the list of required certificates for the chosen specialty ('creative exams', 'extramural', etc.).

- A set of markers of motivation regarding the proposed directions of training, namely the list of training directions for all educational qualification levels in higher educational institution, 'computer science', 'artificial intelligence', 'applied linguistics', etc

- A set of markers of motivation for accepting documents that describe the list of key entry documents and organizational issues that are associated with it ('certificates', 'medical certificate', etc.).

- A set of markers of motivation that characterize the benefits of potential entrant to other entrants ('small academy of sciences', 'participant of the Olympiad', etc.).

- A set of markers of motivation of the participants in the entry campaign, regarding the social and living conditions of studying at universities and the educational process itself ('hostel', 'pool', etc.) Formal definitions of indicators the last four indents are constructed like (7).

The need to determine the relevance of the post is to determine the timing of the relevance of the post to provide a timely response and not to lose the motivation of the participant communication. The motivational intentions of the author of the post vary depending on the time period in relation to the entry campaign.

The need to determine the relevance of a post $-\mathrm{a}$ tuple of five elements:

$$
\begin{gathered}
\text { MRelevance }_{i}= \\
\text { ITimePeriod }_{i} \text {,ITimePeriod }_{i}, \\
=\left\langle\text { IIITimePeriod }_{i}, \text { IVTimePeriod }_{i}\right\rangle, \\
\text { VTimePeriod }_{i}
\end{gathered}
$$

where

$\left\{\text { ITimePeriod }_{i}\right\}_{i=1}^{\text {N(ITimePeriod })} \subset$

ITimePeriod $_{i} \in$

EducMotivMarker - the set of motivational markers that characterize the I and the entry campaign period, IITimePeriod $_{i} \subset$ EducMotivMarker - the set of motivational markers that characterize the II and the entry campaign period, IIITimePeriod $_{i} \subset$ EducMotivMarker - the set of motivational markers that characterize the III and the entry campaign period, IVTimePeriod $_{i} \subset$ EducMotivMarker - the set of motivational markers that characterize the IV and the entry campaign period, VTimePeriod $_{i} \subset$ EducMotivMarker - the set of motivational markers that characterize the $\mathrm{V}$ and the entry campaign period. So:

- A set of markers of motivation characterizing the I entry campaign period (making decisions by prospective entrants in choosing a HEI and training direction). By the time of registration for an external independent assessment, the graduate must determine the list of items to be compiled. During this period, participants are interested in information about the upcoming entry campaign. It is the availability of appropriate certificates that will enable the prospective entrant to submit the documents to the chosen educational institution and specialty. Therefore, the motivational markers of this period will be the 'list of documents', 'what is needed', 'what is the difference between $\mathrm{n}$ the directions of training' and the like.

For each type of markers ITimePeriod $_{i}$ from (6), indicator is defined as follows:

$$
\begin{aligned}
& \text { ITimePeriodIndicator }\left(\text { ITimePeriodMarker }_{i}\right)= \\
& \left.\left\{\begin{array}{c}
\text { Marker(ITimePeriodMarker } \left._{i}\right)_{j}, \\
\omega\left(\text { ITimePeriodMarker }_{i}\right)_{j}
\end{array}\right\rangle\right\}_{j=1}^{N(\text { ITimePeriod })}
\end{aligned}
$$

where $\omega\left(\text { ITimePeriodMarker }_{i}\right)_{j} \in[0,1]-$ the measure of correspondence of the $\mathrm{j}$-th marker to the motivational intent of the $\mathrm{i}$-th entrant.

- A set of markers of motivation that characterize the II stage of the entry campaign. This is one of the most active periods of communicative activity, since it comes at the time of registration on the external testing. Potential entrants are interested in the list of subjects necessary for compiling for admission to the chosen specialty.

- A set of markers of motivation that characterize the III entry period (registration for external 
testing). Therefore, the set of markers of this period include the words 'admission committee', 'rating', 'originals', etc.

- A set of markers of motivation characterizing the I period of the entry campaign (submission of documents and corresponding certificates and higher education institutions and enrollment of entrants for studying in higher education); This period is characterized by active communicative activities for submission of the necessary documents to the university and writing an application for entry. The words 'enrollment', 'appeal', etc. is a set of markers of this period.

- A set of markers of motivation that characterize the $\mathrm{V}$ stage of the entry campaign (the coordination of questions regarding the university's educational activities and social and living conditions). During this period, participants are interested in information on the organization of the educational process of HEI and the organization of social and living conditions of students. The markers of motivation of this period will include the words 'training material', 'department', 'training', etc.

Formal definitions of indicators of the last four indents are constructed like (9).

\subsection{DETECTION OF MOTIVATIONAL INTENTIONS IN THE POST OF ENTRANTS}

The communicative activity of the forum participants arising from the motivational intentions of the author of the post about the chosen discussion of a certain educational topic of a particular section benefits one of the parties of communication or both of them. The value of each post for both communications is different and differs in weight for a particular entry campaign within the chosen higher education institution, and differently influences the decision-making process of both sides of communication.

Each thematic post is a tuple:

$$
=\left\langle\begin{array}{c}
\text { EducationPost }_{l}= \\
\text { EducationSection }_{l}, \text { Author }_{,} \\
{\text {Date, } \text { Content }_{l}, \text { PostMarker }_{l}}
\end{array}\right\rangle
$$

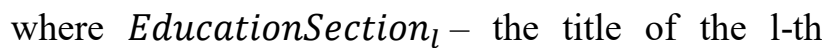
thematic discussion of the educational forum for the entrant, Author - the author of the first post of an educational web-forum for entrants on a certain topic, Date - date of posting, Content C $_{\text {- }}$ informational content of the educational forum for entrants in accordance with the 1-th thematic discussion, PostMarker P $_{l}$ a set of detected markers (Fig. 1):

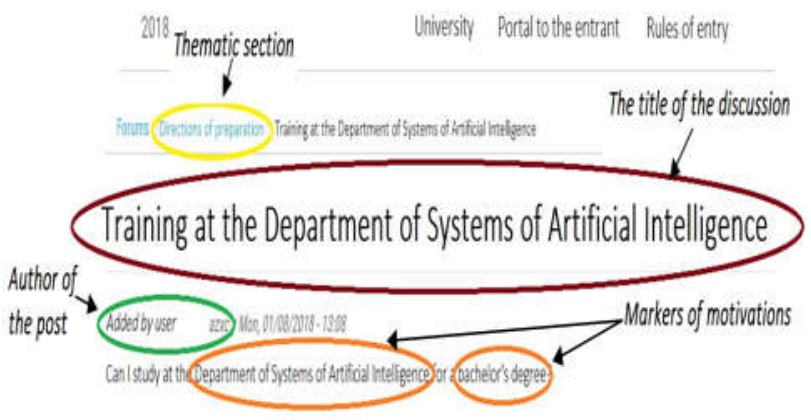

Figure 1 - Detection of motivational markers in the formal structure of posts on the web-forum (http://vstup.lpnu.ua/forum)

To determine the content of the thematic post to motivate the information needs of the entrant, it is necessary to set a functional that takes into account the degree of correspondence of the $\mathrm{j}$-th marker to the motivational intent of the i-th entrant. In general, functional with the result between 0 and 1 is as follows:

$$
\begin{gathered}
\text { Adecuacy }_{\text {MInformation }_{i}}\left(\text { EducationPost }_{l}\right) \\
\geq \alpha
\end{gathered}
$$

where $\alpha \in(0,1]$ - the minimum acceptable value of the marker correspondence to the information needs of the entrant. We can assume that such a motivation is present. Otherwise, it can be argued that such a motivation is not present.

\section{ANALYSIS OF RESULTS}

Formation of educational content, based on the communicative activities of the participants of the web-forum and their motivational intentions, differs from the information content of other communities or forums. So, the feature of specialized educational web-forums is that its participants (potential entrants) are active only for some time: from the beginning of registration and the provision of their data until the necessary information is received. That is why the topics of the forum quickly lose their relevance. As a result of the discussion, the user receives an answer and makes a quick decision. It is worthwhile to note that the content can be NULL, since the corresponding information has already been submitted in a certain way to another section of the forum, or not relevant, for a particular entry campaign.

The distribution of activity for the formation of the content of the web-forum for Lviv Polytechnic National University entrants for 2013-2017 by the periods of the entry campaign is shown in Fig. 2. 


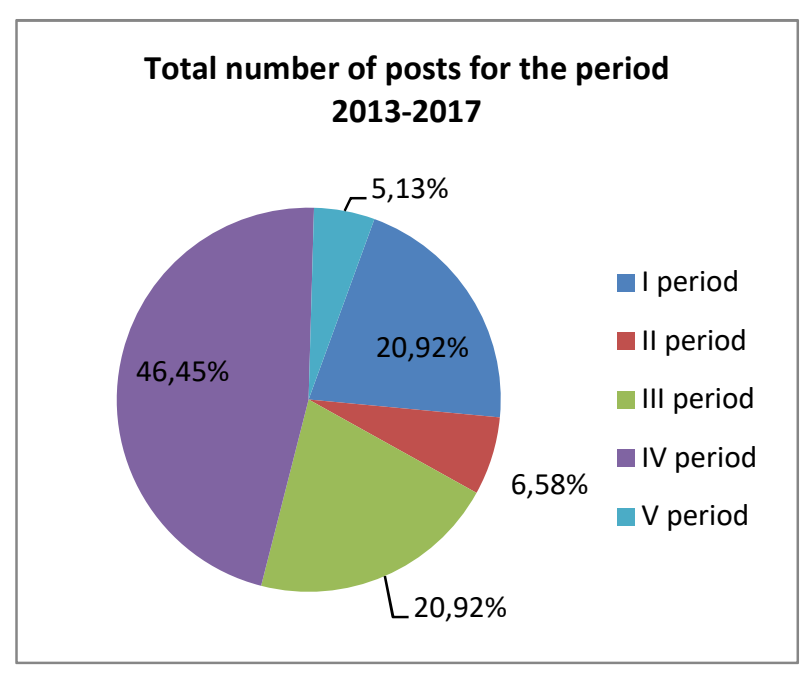

Figure 2 - Distribution of the communicative activity of the web-forum for Lviv Polytechnic National University entrants for 2013-2017 by the periods of the entry campaign

Thus, I, III, IV periods are characterized by active communicative activity of participants of web forums for entrants. Communicative activity during these periods shows that the main processes of decision-making by a potential entrant are in the I, III, IV period. Timely interaction with participants in communicative activities is a positive aspect of these activities for both sides of communication. Namely, a potential entrant quickly receives reliable information from the HEI. The HEI, in its turn, receives information on the main aspects of the entry campaign, which are of interest to entrants at this moment, which makes it possible to influence the decision-making process of these entrants. It should be noted that it is possible to influence the decisions of potential entrants in choosing a specialty and HEI in the I and III periods, and, the HEI can only adjust the activities of future students and expand their areas of interest in relation to selected specializations in the IV period.

Detecting the most active periods of an entry campaign enables to determine the time when it is expedient to use the main resources of communicative activities of the HEI. That is why, the activity of the HEI in other periods should be guided by the maximum presentation of the HEI itself.

Each period of the entry campaign has a predominant theme of the articles, which characterizes the motivational intentions of potential entrants.

The distribution of motivational markers identified in the posters of entrants, the periods of the entry campaign and thematic sections of the web-forum for Lviv Polytechnic National University entrants are presented in Fig. 3.

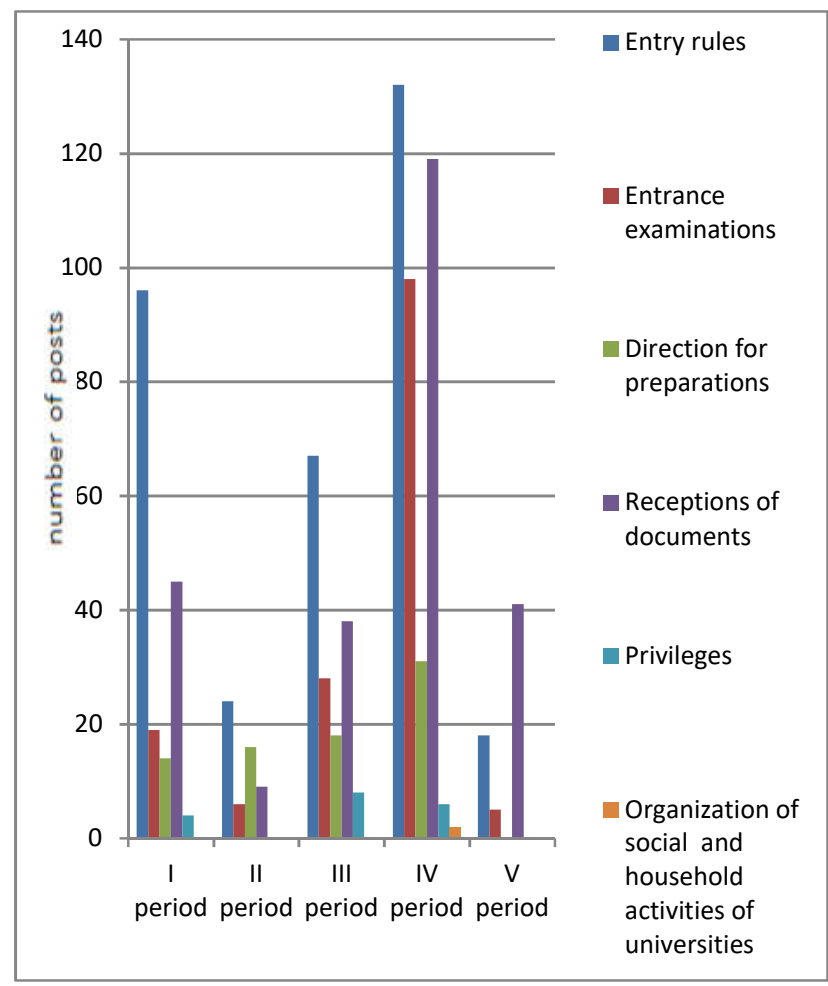

Figure 3 - Distribution of motivational markers found in the posters of entrants, by the periods of the entry campaign and thematic sections of the web-forum for

Lviv Polytechnic National University entrants

The predominant subject of the papers determines the main subjects of each period of the entry campaign.

Distribution of motivational markers, found in the posts of the web-forum for Lviv Polytechnic National University entrants, according to the motivational intentions of the entrants is shown in Fig. 4.

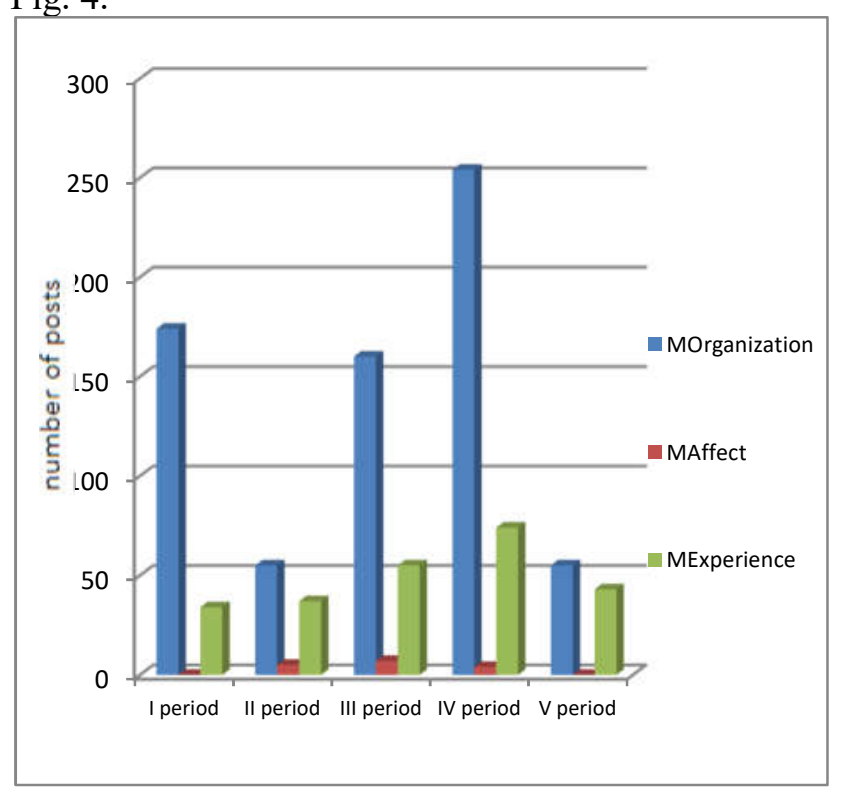

Figure 4 - Distribution of motivational markers, found in the posts of the web-forum (http://vstup.Ipnu.ua/forum), based on the motivational intentions of university entrants 
Identified markers of motivation in the posts of potential entrants in each of the periods of the entry campaign determine the main directions of influence on the decision-making process of these potential entrants.

\section{CONCLUSIONS}

Modeling of the web-forum content forming process enables to extract from the flow of information content the required amount of information (markers of motivation) for the possibility of planning the provision of educational services for the above-mentioned institution.

Obviously, the information content, which is based on the motivational intentions of the participants of the communication, is essential for the formation and development of a virtual forum of entrants. This makes users more active. It is important to note that the constant updating of content is an important factor in supporting the activities of such a web community. Linguistic analysis of individual user posts that form the content of the web-forum due to the isolation of his interests of communication is the basis for vocational guidance work of any higher education institution as timely obtain necessary information from representatives of universities help applicants to quickly decide on the choice in favor of HEI. Therefore, analyzing the posts in this way, one can predict the behavior of a significant part of future students.

In this work, the periods of the campaign are marked, which are characterized by active communicative activity of participants of web forums for entrants. A timely response to these reports may positively affect the decision-making process of these entrants in terms of choosing a specialty and HEI.

Detecting predominantly postings on the webforum for entrants and highlighting motivational intentions from each of the periods of the entry campaign allows to concentrate the attention of the HEI on specific areas of influence on the decisionmaking process by the potential entrant and the precise activities of the HEI at each of these periods.

\section{REFERENCES}

[1] J. Lipicski, M. Medykowski, N. Shakhovska, Yu. Syerov, "Web-community model, based on dataspaces," Proceedings of the International Conference on Intellectual Systems for Decision Making and Problems of Computational Intelligence "ISDMCI'2009", Yevpatoria, 2007, vol. 2, pp. 9-13.
[2] J. Zhang, J.X. Yu, J. Hou, Web Communities: Analysis and Construction, Springer, Heidelberg, 2006, $187 \mathrm{p}$.

[3] P. Zaphiris, C.S. Ang, Social Computing and Virtual Communities, Chapman and Hall/CRC, 2009, $303 \mathrm{p}$.

[4] M. King, A Strategic Assessment of the Higher Education Industry: Applying the Porter's Five Forces for Industry Analysis, 2015, [Online]. Available: https://www.researchgate.net/ publication/254351314.

[5] A. Alkhathlan, A. Al-Daraiseh, "An analytical study of the use of social networks for collaborative learning in higher education," International Journal of Modern Education and Computer Science(IJMECS), vol. 9, no. 2, pp. 1-13, 2017.

[6] Yu. Syerov, S. Fedushko, Z. Loboda, "Determination of development scenarios of the educational Web forum," Proceedings of the XIth International Scientific and Technical Conference, Lviv, 2016, pp. 73-76.

[7] L. Kalashnikova, "Channels of communication cooperation of institution of higher learning with society: short analysis," Management of sociology, Series of Special and Particular Branch Sociology, Doneck: DONDUU, vol. 6, issue 2, pp. 125-134, 2005. (in Russian)

[8] I. Kitaev, "Assessment of training needs in educational planning and management," in Proceedings of the Consultative Policy Forum, Ashgabat, 6-9 September, 1994, $90 \mathrm{p}$.

[9] O. Trach, V. Vus, O. Tymovchak-Maksymets, "Typical algorithm of stage completion when creating a virtual community of a HEI," in Proceedings of the $13^{\text {th }}$ International Conference "Modern Problems of Radio engineering, Telecommunications and Computer Science" (TCSET'2016), 2016, pp. 849-851.

[10] Yu. Syerov, A. Peleschyshyn, S. Fedushko, "The computer-linguistic analysis of sociodemographic profile of virtual community member," International Journal of Computer Science and Business Informatics (IJCSBI), vol. 4, issue 1, pp. 1-13, 2013.

[11] S. Fedushko, "Development of a software for computer-linguistic verification of sociodemographic profile of web-community member," Webology, vol.11, no. 2, Article 126, 2016.

[12] S. Prabhumoye, S. Choudhary, E. Spiliopoulou, Ch. Bogart, C. Penstein Rose, A.W. Black, "Linguistic markers of influence in informal interactions," Proceedings of the Second Workshop on Natural Language Processing 
and Computational Social Science, Vancouver, Canada, August 3, 2017, pp. 53-62.

[13] P. Zhezhnych, O. Markiv, "A linguistic method of web-site content comparison with tourism documentation objects," in Proceedings of 12 th International Scientific and Technical Conference Computer Science and Information Technologies (CSIT'2017), Lviv, 2017, pp. 340-343.

[14] P. Zhezhnych, O. Markiv, "Recognition of tourism documentation fragments from webpage posts," in Proceedings of the 14th International Conference on Advanced Trends in Radioelectronics, Telecommunications and Computer Engineering (TCSET), 2018, pp. 948-951.

[15] D.Carmichael, C.MacEachen, "Heuristic evaluation of the use of Blackboard \& Facebook groups in computing higher education," International Journal of Modern Education and Computer Science (IJMECS), vol. 9, no. 6, pp. 1-8, 2017.

[16] S. Maslovskyi, A. Sachenko. "Adaptive test system of student knowledge based on neural networks," Proceedings of the $8^{\text {th }}$ IEEE International Conference on Intelligent Data Acquisition and Advanced Computing Systems: Technology and Applications (IDAACS'2015), 2015, pp. 940-944.

[17] V. Savicki, D. Lingenfelter, D. Kelley, “Gender language style and group composition in internet discussion groups," Journal of Computer-Mediated Communication, vol. 2, issue 3, December 1996. [Online]. Available: https://doi.org/10.1111/j.1083-6101.1996.tb00 191.x

[18] A. Peleshchyshyn, Z. Holub, I. Holub, "Methods of real-time detecting manipulation in online communities," in Proceedings of the 11th International Scientific and Technical Conference on Computer Sciences and Information Technologies, 2016, pp. 15-17.

[19] S. Putrevu, K.R. Lord, "Processing Internet communications: a motivation, opportunity and ability framework," Journal of Current Issues and Research in Advertising, vol. 25, issue 1, pp. 45-59, 2012.

[20] K. Crowston, I. Fagnot, "Stages of motivation for contributing user-generated content: A theory and empirical test," International Journal of Human-Computer Studies, vol. 109, pp. 89-101, 2018.

[21] N. Mikhno, L. Sorokina, "Trend analysis of the educational choice of university entrants as tool to improve the quality of educational service," International Journal of Information and
Communication Technologies in Education, vol. 6, issue 3, pp. 36-39, 2017.

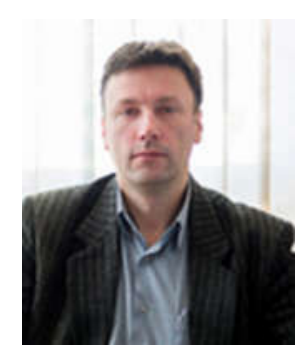

Pavlo I. Zhezhnych is Professor, Sc.D, professor at the department of Social Communication and Information Science, Institute of Humanities and Social Sciences, Lviv Polytechnic National University. In 1996 he graduated from the Faculty of Applied Mathematics, at Lviv Franko State University, the specialty "Applied mathematics". In 2001 he defended his thesis for the degree of Candidate of technical sciences in Lviv Polytechnic National University. In 2009 he defended his thesis for the degree of doctor of technical sciences. His Sc.D. thesis title is "Methods and means of relational time-dependent databases organizing". The scientific and professional interests are focused in the fields of relational and temporal database modeling, Data analysis, Data mining, Information security, Web technologies.

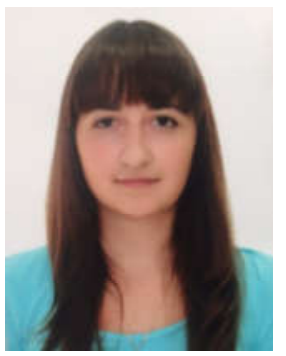

Anna Yu. Shilinh is a postgraduate student at the department of Information Systems and Networks at Lviv Polytechnic National University. She graduated from Drogobych State Pedagogical University, specialty "Informatics. Applied Mathematics". Her fields of scientific activity are internet linguistics, research on informational activities in the web space.

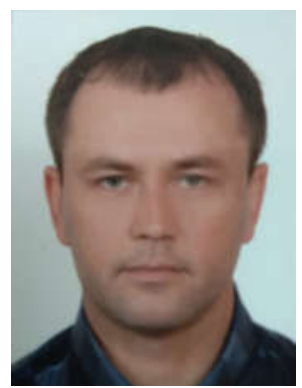

Viktor A. Melnyk is a professor of the Department of Information Technologies Security at Lviv Polytechnic National University, Ukraine. He was awarded with the academic degrees of Philosophy Doctor in 2004, and Doctor of Technical Sciences in 2013 at Lviv Polytechnic National University. He has scientific, academic and hands-on experience in the field of computer systems research and design, proven contribution into IP Cores design methodology and high-performance reconfigurable computer systems design methodology. He is experienced in computer data protection, including cryptographic algorithms, cryptographic processors design and implementation, wireless sensor network security. 